\title{
Boundary Crossing: Meaningfully Engaging Religious Traditions and Religious Institutions in Public Health
}

\author{
Katelyn N.G. Long ${ }^{1,2, *}$, Ryan J. Gregg ${ }^{3}$, Tyler J. VanderWeele ${ }^{1,2,4}$, Doug Oman ${ }^{5}$ and \\ Lance D. Laird ${ }^{6,7}$ \\ 1 Department of Epidemiology, Harvard T.H. Chan School of Public Health, Boston, MA 02115, USA \\ 2 Human Flourishing Program, Institute for Quantitative Social Science, Harvard University \\ Cambridge, MA 02138, USA \\ 3 Committee on the Study of Religion, Harvard University, Cambridge, MA 02138, USA \\ 4 Department of Biostatistics, Harvard T.H. Chan School of Public Health, Boston, MA 02115, USA \\ 5 School of Public Health, University of California, Berkeley, Berekeley, CA 94720, USA \\ 6 Department of Family Medicine and Division of Graduate Medical Sciences, Boston University School of \\ Medicine, Boston, MA 02118, USA \\ 7 Graduate Division of Religious Studies, Boston University, Boston, MA 02115, USA \\ * Correspondence: knlong@hsph.harvard.edu
}

Received: 6 June 2019; Accepted: 25 June 2019; Published: 29 June 2019

check for updates

\begin{abstract}
Interest in religion and spirituality continues to grow among public health practitioners, researchers, and scholars. While there have been several recent landmark publications and efforts to understand the intersections of religion, spirituality, and public health, work remains to be done. In this commentary, we outline three challenges that impede more substantive engagement with religion and spirituality from the public health perspective; namely, the controversial aspects of religion, the perception of religion as a private matter, and limited academic space for coursework around religion and spirituality within public health training. We then describe a series of recommendations that might foster better scholarship and praxis at the crossroads of public health, religion, and spirituality: forming interdisciplinary teams, engaging a wider body of literature, building relationships with faith-inspired colleagues and communities, and considering the goals and ends of communities we serve. We remain hopeful that through ongoing dialogue and academic humility, work exploring the features of religion, spirituality, and public health will yield richer understanding of our shared humanity and the features that give rise to life.
\end{abstract}

Keywords: religion; spirituality; faith; public health; global health; interdisciplinary scholarship

\section{Introduction}

In their book, Religion and the Health of the Public, Gary Gunderson and James Cochrane outline a comprehensive theoretical framework for understanding and working at the intersections of religion and public health (Gunderson and Cochrane 2012). Among their many contributions, the authors point to the use of the "clumsy" conjunction "and" which often sits between religion and public health as a symbol of the fragmented scholarship that attempts to separate and individually examine these features of the human experience-features which in many cultures cannot be separated from one another (ibid., p. 8). Further in the book, the authors examine the lives of Dr. Martin Luther King Jr., Reverend Theo Kotze, and Era Chandrasekaran as examples of "boundary leaders"; those who are able to operate beyond fixed zones of authority, who are able to see the complexity of the whole, and, through profound relational engagement and influence, work to bring about "new social wholes" 
(ibid., p. 121). The authors note the particular challenge of boundary crossing for religious leaders and academics alike, who are prone to fixed articulations of tradition and/or tools of abstraction. As the call for papers of this special feature notes, public health research that attempts to engage religion and spirituality often suffers from its own fixed traditions and abstractions that are deeply embedded in the science of population health. As an interdisciplinary author team of public health and religious studies scholars, we reflect on the growing attention to religion and spirituality in the field of public health and highlight some of the persistent challenges that impede richer engagement with religious traditions and institutions. We then outline ideas for ways that we and our colleagues might step beyond our own "boundaries" to participate in scholarship and real-world activity that enables better service to the whole.

\section{Growing Interest in Religion and Spirituality within Public Health}

While the layers of interaction between religion, spirituality, and health can be traced through the centuries, in recent decades several landmark public health efforts, reports, and edited volumes have called attention to the importance of engaging religious traditions, practices, and institutions. Examples at the global level are the inclusion of faith-based health providers in the largely successful $3 \times 5$ initiative to get three million people living with HIV/AIDS on treatment by 2005, launched by the World Health Organization and the Joint United Nations Programme on HIV/AIDS (Karpf 2014), and the development of the United Nations Inter-Agency Task Force on Religion and Development (United Nations 2008). In 2015, The Lancet, one of the world's most influential medical journals (The Lancet 2019), published a special series on faith-based health providers (Summerskill and Horton 2015), unveiled at a conference hosted by the World Bank (World Bank 2015). The Lancet series achieved multiple things by: highlighting the important role that faith-based health providers can play in weak and fragile health systems (Olivier et al. 2015); providing a road map for faith-based and secular partners who hope to navigate dynamics of faith-linked controversies in health (Duff and Buckingham 2015); and illustrating the powerful impact of partnerships vis-à-vis "Safe Burial Protocols", an intervention co-developed by religious and public health leaders that proved pivotal in halting the 2014 Ebola epidemic in West Africa (Marshall and Smith 2015). Further exploring the theme of partnership, a Spring 2019 Special Issue of the American Journal of Public Health highlighted successful collaborations between faith groups and secular public health agencies (Idler et al. 2019), including the influential role of the Black Church in Public Health (Brewer and Williams 2019), programs to improve access to healthy foods and safe places for physical activity (Hardison-Moody and Yao 2019), and successful influenza prevention partnerships among hard-to-reach, vulnerable populations in the US (Kiser and Lovelace 2019). The series release was celebrated by a conference at Emory University that brought together religious and public health leaders to discuss the articles and their implication for public health practice (Emory University, Religion and Public Health Collaborative 2019).

In the past decade, several books, edited volumes, and landmark studies aimed at public health audiences, further emphasized the important intersections between religion and public health. For example, Ellen Idler's well-known Religion as a Social Determinant of Public Health (Idler 2014) called into question the absence of religion in most public health discourse and explored the multiple levels of powerful interaction between religious institutions and institutions of public health. Susan Holman's Beholden explored the intersections of religion, global health, and human rights (Holman 2015), and most recently, Doug Oman's edited volume Why Religion and Spirituality Matter for Public Health (Oman 2018a). This volume provided, among other things, rigorous review of biomedical and social science literature on the role of religion and spirituality in a variety of public health domains, finding that while a range of religious factors can have both negative and positive impacts on community health, the overall trend at the individual level tends to be positive (e.g., Oman 2018a). Additionally, in recent years, a number of methodologically rigorous studies found significant and powerful effects of religious community participation on reduced mortality (Li et al. 2016), a six-fold reduction in suicide risk and reduction in depression (VanderWeele et al. 2016), and a battery of positive and protective 
factors related to adolescent health and well-being (Chen and VanderWeele 2018), which collectively build the public health case that to ignore these associations is to be blind to one of the factors shaping population health.

Such initiatives and publications stand as signposts for public health scholarship that takes religion seriously. While the previous paragraphs highlighted content ranging from rigorous empirical studies to qualitative and ethnographic explorations, important work remains to enrich research and practice at the intersections at public health, religion, and spirituality. As is the case for any endeavor that aims to cross disciplinary lines, public health inquiry runs the risk of treating the features of religion and spirituality in light and somewhat reductive terms-failing to do justice to its multi-layered influence on human health and health delivery, to say nothing of its influence on the way people understand the nature of life and being (Laird and Barnes 2008). For example, while it is useful (and challenging) to quantify the number of health facilities operated by religious actors in a particular region or country (Olivier et al. 2015), simply counting the "where" misses the critical "who, why, what, and how" questions that constitute a more complete picture of the interactions between religious traditions, human health, and well-being (ibid). Of course, these questions are much harder to ask, and their answers are difficult to generalize.

Theoretical and methodological hurdles aside, thoughtfully engaging religious traditions and religious institutions in public health is essential for many reasons. The primary reason is the "population" focus within the field of public health (American Association of Public Health 2019). If the health of populations and communities is our mission, then we must take seriously the things that matter to the communities we hope to serve. It is well documented that despite secularization theory's forecast of religion's plodding demise (Taylor 2018, pp. 423-37), religion continues to be a central force in the lives of 84 percent of the world's population (Pew Research Center 2017). In the United States, while formal religious participation is trending downward (Gallup 2018a), religion remains important to Americans, with recent polls finding that 72 percent of people consider religion important, including 51 percent for whom it is "very important" (Gallup 2018b). Simply knowing the percentages of the "religious" or "spiritual," however, is wildly insufficient for meaningful engagement. At a deeper level, the driving motivations of public health researchers and practitioners are to create the conditions that prevent disease, prolong life, and promote health across the lifespan (Winslow 1920). But this begs the question: What does it mean to live? To flourish? To suffer? To die? These are queries for which religious traditions provide unique answers, and if public health practitioners are to operate thoughtfully among religiously diverse communities, we do well to grapple with these questions and answers-existentially for some and pragmatically for others.

\section{Challenges to Meaningful Engagement with Religion and Spirituality}

Given the importance for public health to engage with and learn from religious traditions and communities, why does work at the intersections between public health and religion remain difficult? While there may be many reasons for the challenge, here we suggest three that seem particularly salient within academic public health settings: (1) The controversial aspects of religion; (2) The perception of religion as a private matter; (3) Limited academic space for coursework around religion and spirituality within public health training.

First, it is an undeniable fact that religion has been, and still is, a force for both good and evil in the world, fostering "both benevolence and belligerence, peace and pathos of untold dimensions" (Witte and Green 2011, p. 15). In their work on Religion and Human Rights, Witte and Green begin by summarizing the views of those resistant to religion in a pithy list of adjectives. Many feel that religion is too: patriarchal, hierarchical, dangerous, divisive, and diverse in its demands; "antithetical to the very ideals of pluralism, toleration, and equality inherent in a human rights regime" (Ibid., p. 14). We suggest that it is the controversial and difficult aspects of religion that contribute to the turn away from its inclusion in standard public health discourse, in spite of the many ways religion also contributes to health and well-being. 
Second, secular academic public health is intellectually influenced in great part by enlightenment liberalism, which tends to consign religion to the private domain. The various configurations of this broad historical movement operate within what philosopher Charles Taylor calls an "immanent frame" (Taylor 2018) and contribute to religion being either unreflectively ignored or, in some cases, treated with animosity, particularly in circumstances where it is perceived as a foe to public health conceptions of "health" and "rights." Finally, public health is an inherently broad collection of subfields, ranging from epidemiology, policy, law, economics, environmental health, and social and behavioral science, to name just a few. Academic public health programs are under increasing pressure to teach students essential elements of each core subfield and develop practice-based skills that will serve students well in the current job market—all while also facing demands for shorter, more efficient degree programs. In this light, we acknowledge that the all-too-frequent lack of meaningful consideration of the role of religion and spirituality in public health is also a result of limited time, resources, and institutional capacity.

\section{How Can Public Health Better Engage Religious Traditions and People of Faith?}

In light of these challenges, we suggest four ways that public health academics, researchers, and practitioners can better engage religious traditions, spirituality, and people of faith in our scholarship and our community work: (1) academic and intellectual humility; (2) engagement with a wider range of literature; (3) building relationships with people and communities of faith; (4) considering the goals and ends of communities served by the public health. One or more of these may be appropriate depending on the level of engagement.

First, we suggest the need for academic and intellectual humility. While it is understandably daunting to approach the topics of religion and spirituality, there is a rich world of scholars who are expert in these areas and from whom we can learn, exchange ideas, and collaborate. We posit that interdisciplinary teams or expertise are essential for meaningful work that engages religion, spirituality, and public health. We also suggest that academic humility must be offered from all parties, and that the lexicons, principal concerns, and methodologies of various disciplines be patiently unpacked for colleagues from other backgrounds. Public health, for one, is a profoundly acronym-riddled field. It is easy to forget that our colleagues who work in the faith-community or in academic religion or philosophy might not know what we mean when we say things like "multilaterals are urging FBHPs to engage with the SDGs, particularly in UHC-oriented LMICs". Translation: "Large organizations like the United Nations want to encourage faith groups who work in health to participate in broad global goals for development and health, which are called the Sustainable Development Goals. These organizations also hope faith groups can play a role in health delivery in low-and-middle income countries, and countries that are working to provide universal health coverage to their citizens." Of course, the translated version is much longer and more cumbersome. It takes time and patience to share what we know with our colleagues in other fields, but even more, it takes humility to accept when some of our ideas or closely held assumptions are challenged by colleagues who might see the world-and our action in the world-differently. Although challenging, we suggest that intellectual humility with our academic colleagues is in fact the perfect primer for the humility required for inquiry around religion and spirituality more broadly.

Secondly, we suggest deeper engagement with a wider range of literature. Public health tends to be awash in academic papers and lengthy reports, with preference often going towards the most recent publications. As scientists, staying up to date on the newest research findings is indeed an imperative, but as scholars, our view is limited if we only ever consult the "latest" work and subsequently ignore older ideas and longer running debates about the nature of human life. We recognize that running through our public health publications (and the literature of all academic disciplines) is a relatively uniform implicit view of what Miller (2005) called a person's "Menschenbild—one's fundamental understanding (picture) of the nature of the human person ... parallel to a more familiar term ... Weltanschauung-one's world view or broader understanding of reality" (p. 16). The modern materially oriented scientific view of 
human nature (Menschenbild), like other historical "paradigms" that preceded it, may lack completeness, failing to capture the full spectrum of motives and capacities embedded in human nature-and in particular may present a truncated view of human spiritual motivations and responsiveness. Thus, for public health academics and researchers who have interest in religion, we strongly urge the practice of sustained attention to books, particularly books on history, philosophy, religion and theology (and/or religious texts themselves). Most religious traditions nurture visions of what it means to be fully human, to live in wholeness. "Salvation" and "Shalom" are two such visions of complete human health, including bodies, minds, souls, relationships with others and with the environment.

Despite the competing demands and constraints on graduate public health education that we noted earlier, we nonetheless suggest that public health training would be profoundly enhanced by required coursework in public health humanities, especially including religion. For example, a required lecture, course, or series of reflective seminars that invite engagement with diverse texts and disciplines (including multiple religious traditions), that probe distinct understandings of "the good life". Such a suggestion builds on the growing trend for schools of public health to offer courses on religion and public health (e.g., Boston University, University of California, Berkeley, and Harvard University described in detail in Oman 2018a) or integrated programs that offer both public health and religious training (e.g., Emory University's dual degree program public health and divinity (Emory University 2019), featured in (Oman 2018a)).

We imagine that engaging new kinds of literature-and perhaps integrating new course content in public health education - will provide two unique perspectives to public health practitioners and academics. The first is increased awareness of discussions and debates that take place within religious traditions, and that despite the monolithic ways they tend to be portrayed in popular media, religious traditions are rich, textured, and diverse, with profound capacity for debate and self-critique. For example, in the post-colonial era, Christian medical missions around the world were faced with the realities that they had-either implicitly or explicitly—been involved in colonial administrations and power structures that were rapidly being ousted in countries around the world. A series of consultations held in Tübingen Germany in the 1960s reflect difficult and thoughtful discussions about where Christian missions had gone off course and how they might correct course to advance the healing ministry of the church (Germany 1964). In his work on the role of Christianity in US Health and Development Policy, John Blevins points out that the moral reflections of religious traditions can be particularly instructive for public health practitioners and policy makers (Blevins 2018). He suggests that we can learn from the ways that religious traditions have had to reckon with their complicated histories, and in turn, reflect on the way that we (in public health) "want to tell the history of our work in the glossy pages of annual reports that show smiling mothers and well-fed children" (Ibid., p.183).

Engaging new kinds of literature, particularly religious literature, will also likely-and importantly-emphasize the improbability of comprehensive "value alignment" between religious and secular actors. As theologians Miroslav Volf and Matthew Croasmun point out, there is no avoiding contestations of visions of truth inherent in religion (Volf and Croasmun 2019). But working from different value frameworks need not rule out the possibility of work towards mutual interests and common causes. As Dean Pallant notes in his work on Salvation Army Hospitals referencing a philosophical term "telos" meaning "end", "purpose", or "goal"; "mutual interest does not require people to accept a shared telos but opens up the potential for working together despite alternative teloi."(Pallant 2012, p. 74). Pallant goes on to suggest the health and wellbeing of society's poorest members as one such area of mutual or shared concern. He also underscores the need for humility and "dwelling in places of tension" for such a project to succeed.

Third, while academic discussions and books can illuminate various religious ideas, relationships expose us to the lived experience of religion and religious communities. In this light, our third suggestion is for public health practitioners and researchers with an interest in religion to build relationships with people and communities of faith. In our experience, many students in public health may not come from religious backgrounds, making it more difficult to imagine how people of different 
faiths can hold views that run counter to core public health priorities (e.g., birth control, end of life care, circumcision, to name just a few). Even those in the West who do not participate in religious traditions often share a stereotype of religion as "belief" or "creed," a primarily cognitive affair or a concern with "adherence"; whereas practitioners of religion are often diverse, creative, adaptive, and less predictable than we assume. They are contesting, debating and changing their own traditions in relation to their shifting social, natural, and political environment. Likewise, religious symbols, texts, and rituals are often effective precisely because they have multiple meanings and interpretations. They may draw communities together or create conflict over these interpretations. When they draw communities together, they enhance social bonds, providing support, increasing resilience in the face of suffering, and sharing resources for those most vulnerable in society. When they create conflict, they can harden divisions, alienate and marginalize or scapegoat the vulnerable. So, how can we cultivate such relational skills and openness to other "lifeworlds" and "healthwords" in our public health education and practice (Kleinman 2006; Gunderson and Cochrane 2012; Laird and Barnes 2008)? Some ideas are to study or work alongside those who are deeply engaged in community-based theological, philosophical, or artistic projects. For public health students, practicums, interviews, and community-based internships are another way to gain exposure to religious traditions within the community. These relational encounters can serve us well as we aspire to ask better questions about the interactions between religion, spirituality, and public health, as we seek rich and nuanced interpretations of our data, and as we aspire to participate in insightful, boundary-crossing scholarship and partnerships that help build a better whole.

We recognize that our first three recommendations are best-suited for those in public health with interest in religion and spirituality. Consequentially, our final recommendation is meant for broader application in public health practice and scholarship, including those for whom the religion-health interface does not seem particularly central. It is simply this: routine consideration of the principal goals and ends of communities we serve, acknowledging the way these goals and ends likely include, but extend far beyond, "physical health". We speak from experience that this final consideration has the capacity to guide questions and practice in new directions. For example, how do the values and practices of minority religious groups alter trajectories within institutions of medicine and public health (Laird et al. 2007)? How do philosophical and theological conceptions of the good life inform modern understandings of human flourishing and spiritual well-being (VanderWeele 2017; VanderWeele et al. 2019)? What are the ways in which a person's or community's highest or more tenaciously held goals, whatever they may be, "get into the body" (Oman 2018b, p. 297) and how do those link to health (Mahoney et al. 2005; Homan and Boyatzis 2010)? In our view, these types of questions have the capacity to deepen public health scholarship, and importantly, our practice.

\section{Conclusions}

We close where we begin, with a quote from Gunderson and Cochrane:

"The intellectual disciplines and fields of practice of religion and public health leaders differ, with their respective scientific guilds and faith communities seldom in sync. In reality, it nonetheless remains true that religion and health are intimately bound up with each other, within individuals, and the lifeworlds of communities everywhere." (Gunderson and Cochrane 2012, p. 3)

We agree with this assessment and remain hopeful that forums like this Special Issue can help advance the dialogue between our "guilds" and in doing so, yield richer understanding of our shared humanity and the features that give rise to life.

Author Contributions: Conceptualization, K.N.G.L., R.J.G., T.J.V., D.O., L.D.L.; Writing-Original Draft Preparation, K.N.G.L.; Writing-Review \& Editing, K.N.G.L., R.J.G., T.J.V., D.O., L.D.L.; Funding Acquisition, T.J.V.

Funding: This research was supported by Templeton Grant 61075.

Acknowledgments: We are grateful to Veronika Wirtz for her review and helpful comments on earlier versions of the manuscript, including her suggestion for the title. 
Conflicts of Interest: The authors declare no conflict of interest.

\section{References}

American Association of Public Health. 2019. About APHA. Available online: https://www.apha.org/about-apha (accessed on 28 May 2019).

Blevins, John. 2018. Christianity's Role in United States Global Health and Development Policy: To Transfer the Empire of the World. London: Routledge.

Brewer, LaPrincess C., and David R. Williams. 2019. We've Come This Far by Faith: The Role of the Black Church in Public Health. American Journal of Public Health 109: 385-86. [CrossRef] [PubMed]

Chen, Ying, and Tyler J. VanderWeele. 2018. Associations of Religious Upbringing With Subsequent Health and Well-Being From Adolescence to Young Adulthood: An Outcome-Wide Analysis. American Journal of Epidemiology 187: 2355-64. [CrossRef] [PubMed]

Duff, Jean F., and Warren W. Buckingham. 2015. Strengthening of Partnerships between the Public Sector and Faith-Based Groups. The Lancet 386: 1786-94. [CrossRef]

Emory University. 2019. Dual Degree: Master of Public Health (MPH) and Theology. Available online: http://candler.emory.edu/academics/degrees/public-health/index.html (accessed on 31 May 2019).

Emory University, Religion and Public Health Collaborative. 2019. Finding Common Ground: Partnerships in Religion and Public Health. Available online: http://www.rphcemory.org/event/finding-common-groundpartnerships-in-religion-and-public-health/ (accessed on 3 April 2019).

Gallup. 2018a. Church Leaders and Declining Religious Service Attendance. Gallup.Com. Available online: https://news.gallup.com/opinion/polling-matters/242015/church-leaders-declining-religious-serviceattendance.aspx (accessed on 7 September 2018).

Gallup. 2018b. Religion Considered Important to 72\% of Americans. Gallup.Com. Available online: https://news. gallup.com/poll/245651/religion-considered-important-americans.aspx (accessed on 24 December 2018).

Germany, Charles H. 1964. The Healing Ministry: Report on the Tubingen Consultation. International Review of Mission 53: 467-75. [CrossRef]

Gunderson, Gary, and Jim Cochrane. 2012. Religion and the Health of the Public: Shifting the Paradigm. New York: Palgrave Macmillan.

Hardison-Moody, Annie, and Julia Yao. 2019. Faithful Families, Thriving Communities: Bridging Faith and Health Through a State-Level Partnership. American Journal of Public Health 109: 363-68. [CrossRef] [PubMed]

Holman, Susan R. 2015. Beholden: Religion, Global Health, and Human Rights, 1st ed.Oxford and New York: Oxford University Press.

Homan, Kristin J., and Chris J. Boyatzis. 2010. Religiosity, Sense of Meaning, and Health Behavior in Older Adults. The International Journal for the Psychology of Religion 20: 173-86. [CrossRef]

Idler, Ellen L., ed. 2014. Religion as a Social Determinant of Public Health. Oxford and New York: Oxford University Press, Available online: http://www.oxfordscholarship.com/view/10.1093/acprof:oso/9780199362202.001.0001/ acprof-9780199362202 (accessed on 28 May 2019).

Idler, Ellen, Jeff Levin, Tyler J. VanderWeele, and Anwar Khan. 2019. Partnerships Between Public Health Agencies and Faith Communities. American Journal of Public Health 109: 346-47. [CrossRef] [PubMed]

Karpf, Ted. 2014. Faith and Health: Past and Present of Relations between Faith Communities and the World Health Organization. Christian Journal for Global Health, 1. [CrossRef]

Kiser, Mimi, and Kay Lovelace. 2019. A National Network of Public Health and Faith-Based Organizations to Increase Influenza Prevention Among Hard-to-Reach Populations. American Journal of Public Health 109: 371-77. [CrossRef] [PubMed]

Kleinman, Arthur. 2006. What Really Matters: Living a Moral Life Amidst Uncertainty and Danger. Cary: Oxford University Press USA-OSO.

Laird, Lance D., and Linda L. Barnes. 2008. Religion and Healing. In International Encyclopedia of Public Health. Edited by Stella Quah and Kristian Heggenhougen. Amsterdam: Elsevier, pp. 514-19.

Laird, Lance D., Mona M. Amer, Elizabeth D. Barnett, and Linda L. Barnes. 2007. Muslim Patients and Health Disparities in the UK and the US. Archives of Disease in Childhood 92: 922-26. [CrossRef] [PubMed]

Li, Shanshan, Meir J. Stampfer, David R. Williams, and Tyler J. VanderWeele. 2016. Association of Religious Service Attendance With Mortality Among Women. JAMA Internal Medicine 176: 777-85. [CrossRef] [PubMed] 
Mahoney, Annette, Robert A. Carels, Kenneth I. Pargament, Amy Wachholtz, Laura Edwards Leeper, Mary Kaplar, and Robin Frutchey. 2005. The Sanctification of the Body and Behavioral Health Patterns of College Students. The International Journal for the Psychology of Religion 15: 221-38. [CrossRef]

Marshall, Katherine, and Sally Smith. 2015. Religion and Ebola: Learning from Experience. The Lancet 386: e24-e25. [CrossRef]

Miller, W. R. 2005. What is human nature? Reflections from Judeo-Christian perspectives. In Human Nature, Motivation, and Change: Judeo-Christian Perspectives on Psychology. Edited by William R. Miller and Harold D. Delaney. Washington: American Psychological Association, Available online: https://doi.org/10.1037/ 10859-001 (accessed on 3 June 2019).

Olivier, Jill, Clarence Tsimpo, Regina Gemignani, Mari Shojo, Harold Coulombe, Frank Dimmock, Minh Cong Nguyen, Harrison Hines, Edward J Mills, Joseph L Dieleman, and et al. 2015. Understanding the Roles of Faith-Based Health-Care Providers in Africa: Review of the Evidence with a Focus on Magnitude, Reach, Cost, and Satisfaction. The Lancet 386: 1765-75. [CrossRef]

Oman, Doug. 2018a. Why Religion and Spirituality Matter for Public Health: Evidence, Implications, and Resources. Religion, Spirituality and Health: A Social Scientific Approach. Cham: Springer International Publishing, Available online: https://www.springer.com/us/book/9783319739656 (accessed on 29 May 2019).

Oman, Doug. 2018b. Questions on Assessing the Evidence Linking Religion/Spirituality to Health. In Why Religion and Spirituality Matter for Public Health: Evidence, Implications, and Resources. Edited by Doug Oman. Cham: Springer International Publishing, pp. 283-302. [CrossRef]

Pallant, Dean. 2012. Keeping Faith in Faith-Based Organizations: A Practical Theology of Salvation Army Health Ministry. Eugene: Wipf \& Stock Pub.

Pew Research Center. 2017. The Changing Global Religious Landscape. Available online: https://www.pewforum. org/2017/04/05/the-changing-global-religious-landscape/ (accessed on 28 May 2019).

Summerskill, William, and Richard Horton. 2015. Faith-Based Delivery of Science-Based Care. The Lancet 386: 1709-10. [CrossRef]

Taylor, Charles. 2018. A Secular Age, Reprint Edition ed. Belknap Press.

The Lancet. 2019. About the Lancet. Available online: https://www.journals.elsevier.com/the-lancet (accessed on 28 May 2019).

United Nations. 2008. United Nations Inter-Agency Consultation on Engagement with Faith-Based Organizations 2008. Joint Learning Initiative. Available online: https://jliflc.com/resources/united-nations-inter-agencyconsultation-on-engagement-with-faith-based-organizations-2008/ (accessed on 28 May 2019).

VanderWeele, Tyler J. 2017. On the Promotion of Human Flourishing. Proceedings of the National Academy of Sciences USA 114: 8148-56. [CrossRef] [PubMed]

VanderWeele, Tyler J., Shanshan Li, Alexander C. Tsai, and Ichiro Kawachi. 2016. Association Between Religious Service Attendance and Lower Suicide Rates among US Women. JAMA Psychiatry 73: 845-51. [CrossRef] [PubMed]

VanderWeele, Tyler J., N. G. Long Katelyn, and Michael J. Balboni. 2019. Christian Spiritual Well-Being: Long-Form and Short-Form Questionnaires. Harvard University Technical Report. Cambridge: Harvard University.

Volf, Miroslav, and Matt Croasmun. 2019. Six Traits of a Pluralist Christian Vision of Human Flourishing. The Christian Century. Available online: https://www.christiancentury.org/article/critical-essay/six-traitspluralist-christian-vision-human-flourishing (accessed on 6 February 2019).

Winslow, Charles Edward Amory. 1920. The Untilled Fields of Public Health. Science 51: 23-33. [CrossRef] [PubMed]

Witte, John, and M. Christian Green, eds. 2011. Religion and Human Rights: An Introduction, 1st ed.Oxford and New York: Oxford University Press.

World Bank. 2015. Religion and Sustainable Development \& Lancet Series Launch. Joint Learning Initiative. Available online: https://jliflc.com/sessions/rsd-opening-session-lancet-series-launch/ (accessed on 28 May 2019).

(C) 2019 by the authors. Licensee MDPI, Basel, Switzerland. This article is an open access article distributed under the terms and conditions of the Creative Commons Attribution (CC BY) license (http://creativecommons.org/licenses/by/4.0/). 